\title{
Molecular Imaging for Integrated Medical Therapy and Drug Development
}

N. Tamaki and Y. Kuge, eds.

New York, NY: Springer, 2009, 303 pages, $\$ 189$

This book documents the proceedings of "Molecular Imaging for Integrated Medical Therapy," an international symposium held March 13-14, 2009, at Hokkaido University, Sapporo, Japan.

The book is divided into 4 parts and 28 presentations, with multiple authors for each presentation, and an introductory overview by the editors on advances in molecular imaging.

Part 1 is 8 presentations on various topics such as hypoxia imaging, imaging for assessment and response to tumor malignancy, new PET and hybrid PET scanners, imaging of atherosclerotic plaque, and quantification of myocardial blood flow using ${ }^{82} \mathrm{Rb}$. Part 2 (8 presentations) deals with molecular imaging for regenerative treatment. The presentations in this part describe implications for regenerative treatment of the heart, imaging of angiogenesis, regeneration of articular cartilage, and the use of bone marrow stromal cell transplantation in various neurologic problems.

Six papers are included in part 3, which presents future perspectives on brain research. Some of the topics in this part are chronotherapeutics, cell death and autophagy, bioluminescent imaging, and transporters. Part 4 consists of 6 papers presenting recent trends in drug development.
This book is intended for researchers involved in molecular imaging or drug development and clinicians who treat patients with or without cancer. The material will be useful to individuals familiar with this discipline and those who are new to this discipline and will likely be involved with personalized medical care. The proceedings are now 3 years old and new research and technology has evolved, but the book can be used as an introduction to this field.

The proceedings read well, and though the images are good, some of the legends for black-and-white images describe findings in color. The paper quality is good. This book is recommended for use in libraries rather than for individuals given that newer data can be obtained online.

Aurelio Matamoros, Jr.

M.D. Anderson Cancer Center

1515 Holcombe Blvd.

Unit 1473

Houston, TX 77030

E-mail: amatamor@mdanderson.org

COPYRIGHT (C) 2012 by the Society of Nuclear Medicine, Inc.

Published online Jun. 6, 2012.

DOI: $10.2967 /$ jnumed. 112.105486 